\title{
Aftershock distribution of the 2004 Mid Niigata Prefecture Earthquake derived from a combined analysis of temporary online observations and permanent observations
}

\author{
Takuo Shibutani ${ }^{1}$, Yoshihisa Iio $^{1}$, Satoshi Matsumoto ${ }^{3}$, Hiroshi Katao ${ }^{1}$, Takeshi Matsushima ${ }^{3}$, Shiro Ohmi $^{1}$, Fumiaki Takeuchi ${ }^{1}$, \\ Kenji Uehira $^{3}$, Kin'ya Nishigami ${ }^{1}$, Bogdan Enescu ${ }^{1}$, Issei Hirose ${ }^{1}$, Yasuyuki Kano ${ }^{2}$, Yuhki Kohno ${ }^{4}$, Masahiro Korenaga ${ }^{4}$, \\ Yutaka Mamada $^{1}$, Masatoshi Miyazawa ${ }^{1}$, Ken'ichi Tatsumi $^{1}$, Tomotake Ueno ${ }^{2}$, Hiroo Wada ${ }^{1}$, and Yohei Yukutake ${ }^{2}$ \\ ${ }^{1}$ Disaster Prevention Research Institute, Kyoto University, Uji 611-0011, Japan \\ ${ }^{2}$ Graduate School of Science, Kyoto University, Kyoto 606-8502, Japan \\ ${ }^{3}$ Institute of Seismology and Volcanology, Faculty of Sciences, Kyushu University, Shimabara 855-0843, Japan \\ ${ }^{4}$ Graduate School of Sciences, Kyushu University, Fukuoka 812-8581, Japan
}

(Received February 16, 2005; Revised May 6, 2005; Accepted May 15, 2005)

\begin{abstract}
The 2004 Mid Niigata Prefecture Earthquake $(M j=6.8)$ occurred on 23 October 2004 in the northeastern part of the Niigata-Kobe Tectonic Zone where large contraction rates were observed. The mainshock was followed by an anomalously intense aftershock activity that included nine $\mathrm{Mj} \geq 5.5$ aftershocks. We deployed three temporary online seismic stations in the aftershock area from 27 October, combined data from the temporary stations with those from permanent stations located around the aftershock area, and determined the hypocenters of the mainshock and aftershocks with a joint hypocenter determination (JHD) technique. The resulting aftershock distribution showed that major events such as the mainshock, the largest aftershock $(\mathrm{Mj}=6.5)$, the aftershock on 27 October $(\mathrm{Mj}=6.1)$, etc. occurred on different fault planes that were located nearly parallel or perpendicular to each other. This might be due to heterogeneous structure in the source region. The strain energy was considered to have been enough accumulated on the individual fault planes. These features are probably a cause of the anomalous intensity of the aftershock activity.
\end{abstract}

Key words: The 2004 Mid Niigata Prefecture Earthquake, aftershock distribution, complexity of earthquake faults, temporary online aftershock observations.

\section{Introduction}

The 2004 Mid Niigata Prefecture Earthquake occurred on 23 October 2004 with the Japan Meteorological Agency (JMA) magnitude (Mj) of 6.8 (Fig. 1). The maximum intensity of VII in JMA scale and the maximum acceleration of 1,722 gal were observed at Kawaguchi Town which is located in the vicinity of the epicenter of the mainshock (Japan Meteorological agency, 2004). This earthquake killed 40 people and injured more than 4,600 people. It severely destroyed $\sim 5,000$ houses and partially $\sim 100,000$ houses.

The mainshock was followed by four aftershocks with $\mathrm{Mj} \geq 6.0$ and four with $5.5 \leq \mathrm{Mj}<6.0$. The remarkable feature of this earthquake was that much more larger aftershocks $(\mathrm{Mj} \geq 5.5)$ occurred than those in the 2000 Western Tottori Earthquake $(\mathrm{Mj}=7.3)$ and in the 1995 Hyogo-ken Nanbu (Kobe) Earthquake $(\mathrm{Mj}=7.3)$. In the case of the 2000 Western Tottori Earthquake, there was only one aftershock with $\mathrm{Mj} \geq 5.5$ and one with $5.0 \leq \mathrm{Mj}<5.5$. In the case of the 1995 Kobe Earthquake, there were six aftershocks with $5.0 \leq \mathrm{Mj}<5.5$. The feature that many larger aftershocks occurred affected the lives of refugees,

Copy right(c) The Society of Geomagnetism and Earth, Planetary and Space Sciences (SGEPSS); The Seismological Society of Japan; The Volcanological Society of Japan; The Geodetic Society of Japan; The Japanese Society for Planetary Sciences; TERRAPUB who could not go home because of fears that their houses would collapse due to strong shaking.

The 2004 Mid Niigata Prefecture Earthquake occurred in the Niigata-Kobe Tectonic Zone in which large strain rates ( $>0.1 \mathrm{ppm} / \mathrm{y}$ contraction) were found from GPS data analyses (Sagiya et al., 2000). Many large earthquakes occurred along this tectonic zone such as the 1964 Niigata Earthquake $(\mathrm{Mj}=7.5)$, the 1847 Zenkoji Earthquake $(\mathrm{M}=$ 7.4), the 1828 Echigo-Sanjo Earthquake $(\mathrm{M}=6.9)$ in the neighboring areas of the 2004 earthquake (Sagiya et al., 2000).

We deployed three temporary online seismic stations just above the aftershock area in order to constrain focal depths and mechanisms of aftershocks. We combined data from the temporary stations and from permanent stations around the aftershock area, and relocated aftershocks with a joint hypocenter determination (JHD) technique. The purposes of this study are to discuss the source process of the earthquake with the improved aftershock distribution and to clarify the relation between the feature that many larger aftershocks occurred and the fact that the earthquake occurred in the Niigata-Kobe Tectonic Zone.

\section{Data and Method}

The distribution of 60 stations used in this study is shown in Fig. 1. DP.TDOM, DP.OJKW and DP.YMKS are the 


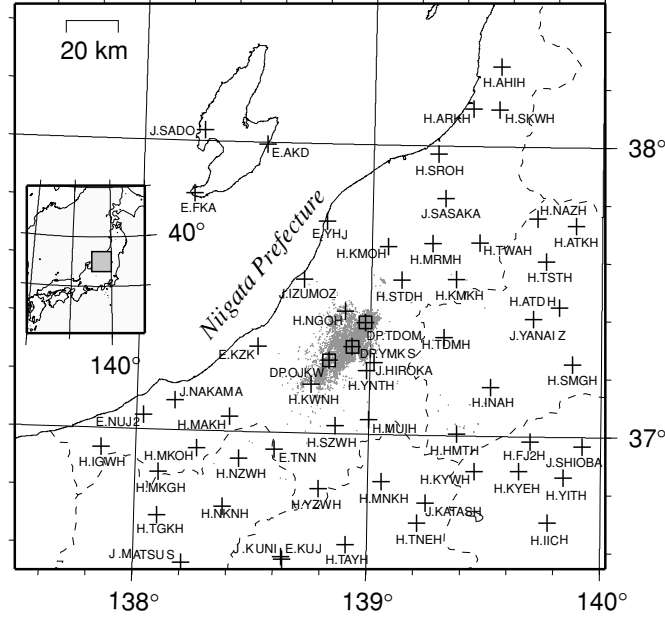

Fig. 1. Map showing the location of the stations (cross with square: temporary online, cross: permanent online) used in this study. Gray dots denote the aftershocks to be relocated in this study. The dashed lines indicate the borders of prefectures. In the inset map the target area is shown by the dark gray rectangle with respect to greater parts of Japan Islands.

temporary stations at which three components of short period ( $1 \mathrm{~s})$ velocity-type seismometers were installed and the waveform data digitized at the rate of $100 \mathrm{~Hz}$ were sent through satellite telemetry systems (Urabe et al., 1998). We started the operations at DP.TDOM and DP.OJKW on 27 October. The dynamic range of the satellite telemetry system used in both the stations was $120 \mathrm{~dB}$. We could use AC power at DP.TDOM, however, we had to use a portable-type generator at DP.OJKW. The observation at DP.YMKS was started on 29 October. The dynamic range of the satellite telemetry system used in this station was $142 \mathrm{~dB}$. We used more than 15 car butteries to operate the system because no AC power was available and all people had already evacuated their home town. The others are the permanent online stations operated by National Research Institute for Earth Science and Disaster Prevention (NIED), JMA and University of Tokyo. The waveform data from the permanent stations were also sent to our institute. Both of the data were combined on our monitoring system. We picked $P$ - and $S$-arrival times, $P$ polarities and the maximum amplitudes on the three component waveforms. The accuracies of the arrival times were typically estimated at $0.01-0.04$ s for $P$ and $0.02-0.08$ s for $S$. We also utilized $P$ - and $S$-arrival times from the JMA preliminary catalog.

We selected 1,579 events with the following criteria: (1) the numbers of both $P$ - and $S$-arrival times were greater than or equal to $10,(2)$ the magnitude was greater than or equal to 1.7 , and (3) the period was from 29 October to 31 December in 2004 during which data from the three temporary stations were available. We determined simultaneously the hypocentral parameters, 1-D velocity models of $P$ - and $S$-waves and the travel time corrections of $P$ - and $S$-waves for the 60 stations using a JHD technique (Kissling et al., 1994). In this technique, a positive (negative) station correction means a positive (negative) travel time residual indicating that an observed travel time is larger (smaller) than a theoretical one in an average sense. The weight of the $S$ time was $\sqrt{1 / 1.73}(\approx 0.76)$ of that of the $P$ time.

Then we applied a single-event location procedure with the station corrections and the 1-D $V p$ and $V s$ models and determined 7,257 events which were selected with the following criteria: (1) the number of the $P$ arrival times was greater than or equal to $10,(2)$ the magnitude was greater than or equal to 0.0 , and (3) the period was from 23 October to 31 December in 2004.

\section{Results}

\subsection{JHD relocation}

After the JHD procedure the root mean square (RMS) of the travel time residuals decreased to $0.024 \mathrm{~s}$. The resulting 1 -D velocity models are shown in Fig. 2. $V p$ and $V s$ are well resolved at the depths of down to $17 \mathrm{~km}$, and the standard errors are smaller than $0.05 \mathrm{~km} / \mathrm{s}$ for both the $V p$ and $V s$ at most of the depths. At the depths shallower than $3 \mathrm{~km}$ the obtained $V s$ is significantly lower than the JMA2001 velocity model (Ueno et al., 2002) shown by the broken line, and the $V p / V s$ shows relatively high values ( 2.0). On the other hand, at the depths of 5-17 km both of the $V p$ and $V s$ are slightly higher than the JMA models, and the $V p / V s$ takes values $1.69-1.73$ which agree well with the JMA model.

The resulting station corrections for the $P$ - and $S$-travel times are illustrated in Fig. 3. Large positive travel time residuals are found at stations in Niigata Basin to the west from the source area, whereas negative residuals are found in Echigo Mountains to the east. The large differences in the travel time residuals $(\sim 1 \mathrm{~s}$ for $P$ and $\sim 2 \mathrm{~s}$ for $S)$ between the two areas significantly affected the aftershock locations. As a result of the JHD relocation the hypocenters moved horizontally $\sim 3 \mathrm{~km}$ in the direction of $\sim \mathrm{N} 65^{\circ} \mathrm{W}$ and upwards $\sim 3 \mathrm{~km}$ in the direction of $\sim 45^{\circ}$ from the zenith with respect to the corresponding JMA hypocenters.

\subsection{Single-event relocation}

We examined the distribution of the standard errors of the hypocenters and found that the errors were smaller than $0.31 \mathrm{~km}$ in EW, $0.27 \mathrm{~km}$ in NS and $0.83 \mathrm{~km}$ in Z for more than $90 \%$ of the 7,257 relocated events. Figure 4 shows the distribution of the selected aftershocks with the condition that the errors in all the EW, NS and $\mathrm{Z}$ directions are smaller than $1.0 \mathrm{~km}$. $\sim 93 \%$ of the relocated events were

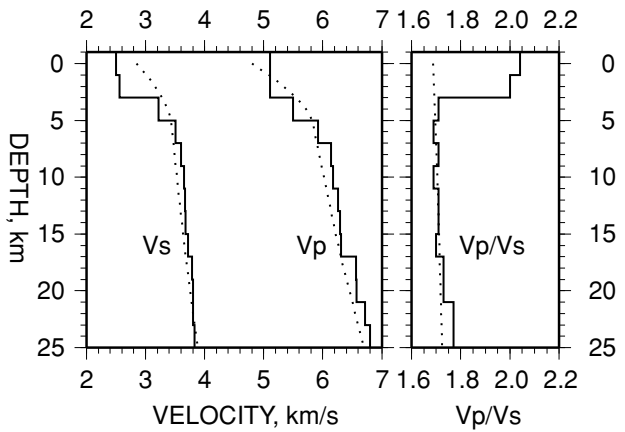

Fig. 2. 1-D velocity models of the $P$ - and $S$-waves from -1 to $25 \mathrm{~km}$ depth. The $V p / V s$ is also shown in the right side. The dotted lines indicate the JMA2001 velocity models. The solid lines denote the velocity models obtained from the JHD relocation. 


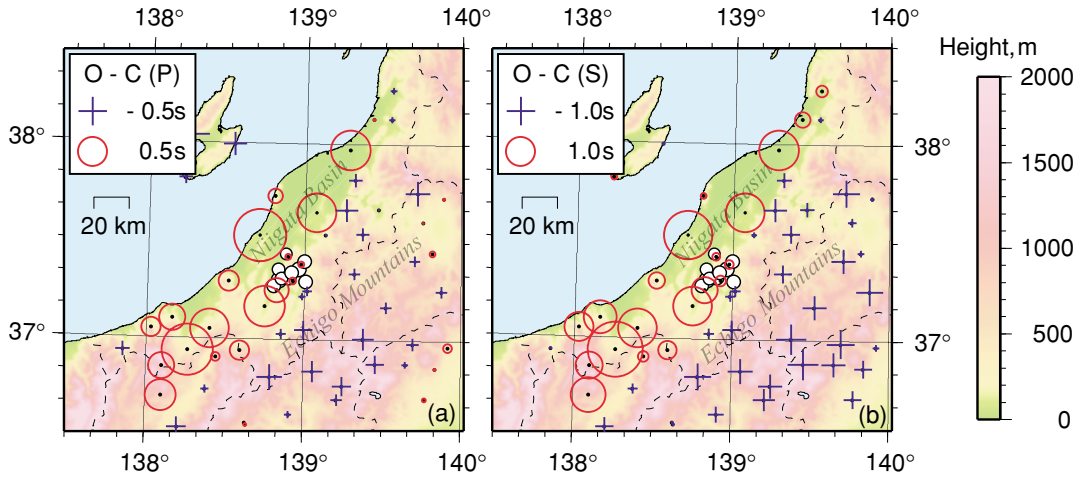

Fig. 3. Travel time corrections for the $P$ - and $S$-waves derived from the JHD relocation. (a) for the $P$ wave and (b) for the $S$ wave. The red circles indicate the positive residuals, while the blue crosses denote the negative residuals. Reference sizes are shown in the insets. The small open circles indicate major events in the 2004 Mid Niigata Prefecture Earthquake sequence. The altitude is shown by the color scale.

Table 1. Hypocenters and mechanisms of the major events.

\begin{tabular}{ccccccc}
\hline & Origin time $(\mathrm{JST})$ & Latitude $\left(^{\circ}\right)$ & Longitude $\left(^{\circ}\right)$ & Depth $(\mathrm{km})$ & $\mathrm{Mj}$ & $(\mathrm{S}, \mathrm{D}, \mathrm{R})\left(^{\circ}\right)$ \\
\hline$\# 1$ & $2004 / 10 / 23$ & 37.3046 & 138.8362 & 11.079 & 6.8 & $(212,47,93)$ \\
& $17: 56: 00.206$ & $(0.104)$ & $(0.096)$ & $(0.371)$ & & $(27,43,87)$ \\
$\# 2$ & $2004 / 10 / 23$ & 37.3613 & 138.9629 & 4.920 & 6.3 & $(218,47,107)$ \\
& $18: 03: 12.704$ & $(0.426)$ & $(0.253)$ & $(1.531)$ & & $(14,45,73)$ \\
$\# 3$ & $2004 / 10 / 23$ & 37.3583 & 138.8336 & 6.627 & 5.7 & $(182,36,61)$ \\
& $18: 07: 30.934$ & $(0.320)$ & $(0.244)$ & $(1.096)$ & & $(37,59,110)$ \\
$\# 4$ & $2004 / 10 / 23$ & 37.2728 & 138.8029 & 4.330 & 6.0 & $(234,37,118)$ \\
& $18: 11: 56.388$ & $(0.307)$ & $(0.310)$ & $(1.955)$ & & $(20,58,70)$ \\
$\# 5$ & $2004 / 10 / 23$ & 37.3174 & 138.8990 & 12.594 & 6.5 & $(221,59,94)$ \\
& $18: 34: 05.682$ & $(0.150)$ & $(0.142)$ & $(0.438)$ & & $(33,31,84)$ \\
$\# 6$ & $2004 / 10 / 23$ & 37.3122 & 138.8510 & 7.642 & 5.7 & $(217,40,107)$ \\
& $19: 45: 56.787$ & $(0.139)$ & $(0.136)$ & $(0.750)$ & & $(16,52,76)$ \\
$\# 7$ & $2004 / 10 / 25$ & 37.3419 & 138.9178 & 13.545 & 5.8 & $(215,53,94)$ \\
$\# 10$ & $06: 04: 57.283$ & $(0.134)$ & $(0.128)$ & $(0.418)$ & & $(29,37,85)$ \\
& $2004 / 10 / 27$ & 37.2980 & 139.0060 & 12.281 & 6.1 & $(218,60,100)$ \\
& $10: 40: 50.221$ & $(0.124)$ & $(0.117)$ & $(0.341)$ & & $(18,32,73)$
\end{tabular}

Standard errors in $\mathrm{km}$ are shown in the parentheses in the latitude, longitude and depth columns. (S, D, R) means the angles of strike, dip and rake of the nodal planes. These values are from NIED MT solutions (NIED, 2004).

selected. The aftershocks distribute beneath Higashiyama and Uonuma Hill Zones, and extend for $\sim 40 \mathrm{~km}$ in the direction of $\mathrm{N} 30^{\circ} \mathrm{E}-\mathrm{S} 30^{\circ} \mathrm{W}$. Major events are listed in Table 1 and shown by the open circles with the numbers. The aftershock distribution is deeper (down to $\sim 15 \mathrm{~km}$ ) at the central part, while it is shallower at the margins. The mainshock (\#1) and the largest aftershock (\#5) started near the deepest points.

Figure 5 shows the $\mathrm{X}-\mathrm{Z}$ cross-sections at every $4 \mathrm{~km}$ from $\mathrm{Y}=16 \mathrm{~km}$ to $\mathrm{Y}=-8 \mathrm{~km}$. From the aftershock distributions we can recognize the fault planes for some of the major events. The translucent red thick (broken) lines indicate the estimated fault plane of the mainshock (\#1), which slopes downward to $\mathrm{N} 60^{\circ} \mathrm{W}$ with the dip of $\sim 50^{\circ}$ and extends from $\mathrm{Y}=\sim-4 \mathrm{~km}$ to $\mathrm{Y}=\sim 12 \mathrm{~km}$. The estimated fault plane of the largest aftershock (\#5) is indicated by the translucent blue thick (broken) lines. It is inclined at $\sim 60^{\circ}$ downward to $\mathrm{N} 60^{\circ} \mathrm{W}$ and stretches from $\mathrm{Y}=\sim-4 \mathrm{~km}$ to $\mathrm{Y}=\sim 8 \mathrm{~km}$. The fault plane of the aftershock occurred on 27 October (\#8) is indicated by the 


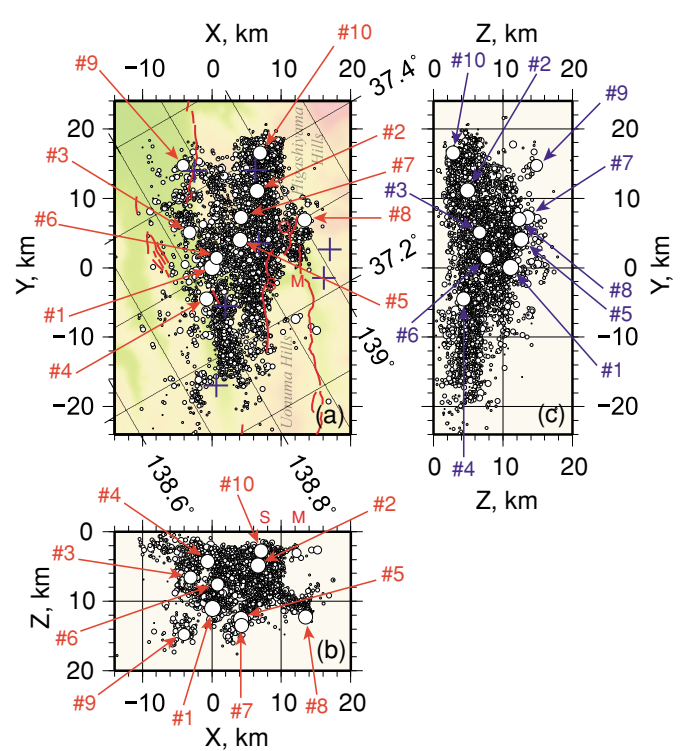

Fig. 4. Distribution of the relocated hypocenters from 23 October to 31 December 2004. (a) Epicenter distribution. Note that the map is rotated anticlockwise by $30^{\circ}$ so that the $\mathrm{Y}$ axis becomes parallel to the aftershock distribution. The background color shows the altitude. The scale is the same as shown in Fig. 3. The red lines indicate active faults, especially the one with the label $\mathrm{M}$ is the Muikamachi Fault, the one with the label $\mathrm{O}$ is the Obiro Fault and the one with the label $\mathrm{S}$ is the Suwatoge Flexure. The blue crosses denote stations. (b) Depth distribution on the $\mathrm{X}-\mathrm{Z}$ cross-section. The symbols $\mathrm{S}$ and $\mathrm{M}$ at the top indicate the locations of the Suwatoge Flexure and the Muikamachi Faults, respectively. (c) Depth distribution on the Y-Z cross-section. The sizes of the circles are proportional to the magnitude of the corresponding aftershocks. The open circles with the numbers are the major events listed in Table 1. The size of the major events are a little bit emphasized.

translucent green thick (broken) lines. In contrast to the above two events (\#1 and \#5), the fault plane of \#8 slopes downward to $\mathrm{S} 60^{\circ} \mathrm{W}$ with the dip of $\sim 30^{\circ}$. It extends from $\mathrm{Y}=\sim 0 \mathrm{~km}$ to $\mathrm{Y}=\sim 12 \mathrm{~km}$. The estimated strike and dip angles are in good agreement with those of the MT solutions (NIED, 2004) shown in Table 1. The translucent yellow thick broken lines might indicate the fault plane of the aftershock (\#4) occurred at 18:11 on 23 October although the estimated dip angle does not agree with that of the MT solution (NIED, 2004).

\section{Discussions}

The station corrections obtained from the JHD relocation shows large positive travel time residuals in the Niigata Basin and negative residuals in the Echigo Mountains. The Niigata Basin and the Higashiyama and Uonuma Hill Zones are located in the northern Fossa Magna, which was formed by the subsidence under the extension tectonics during the Japan Sea opening (16-13.5 Ma). Thick marine sediments up to $7 \mathrm{~km}$ were deposited in this sequence (Takano, 2002). These low velocity materials can cause the large positive travel time residuals.

Our JHD relocation in which the large differences in the travel time residuals between the Niigata Basin and the Echigo Mountains were taken into account shifted the hypocenters $\sim 3 \mathrm{~km}$ to the west-northwest from the corresponding JMA hypocenters. This feature was consistent with the source models derived from crustal movement data

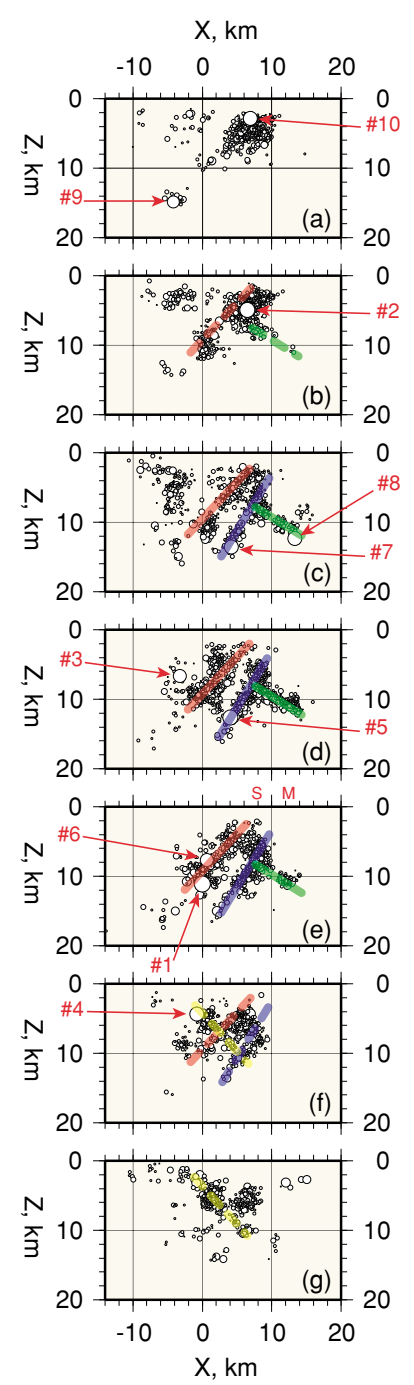

Fig. 5. Depth distribution of the relocated hypocenters on the $X-Z$ cross-sections at (a) $\mathrm{Y}=16 \mathrm{~km}$, (b) $\mathrm{Y}=12 \mathrm{~km}$, (c) $\mathrm{Y}=8 \mathrm{~km}$, (d) $\mathrm{Y}=4 \mathrm{~km}$, (e) $\mathrm{Y}=0 \mathrm{~km}$, (f) $\mathrm{Y}=-4 \mathrm{~km}$ and (g) $\mathrm{Y}=-8 \mathrm{~km}$. In these cross-sections, events located in the range $\pm 2 \mathrm{~km}$ from the planes were plotted. The translucent red, blue and green thick lines indicate the estimated fault planes. The symbols $\mathrm{S}$ and $\mathrm{M}$ at the top of (e) indicate the locations of the Suwatoge Flexure and the Muikamachi Faults, respectively. The open circles with the numbers are the major events listed in Table 1.

from leveling and GPS observations (Geographical Survey Institute, 2004) and with those derived from crustal deformation detected using SAR interferometry (Ozawa et al., 2005). This supports that the JHD relocation could improve the absolute locations of the hypocenters.

The mainshock fault plane estimated by the aftershock distribution (the translucent red thick line in Fig. 5(e)) intersects the surface near the Suwatoge Flexure, while the fault plane of the largest aftershock (\#5) (the translucent blue thick line in Fig. 5(d)) cuts the surface near the Muikamachi Fault (Fig. 4(a)). The Suwatoge Flexure and the Muikamachi Fault have moved as reverse type faults dipping northwestward (Kim, 2004). Ground deformations such as horizontal shortenings, landslides and fissures were convergently observed near the faults (Kim and Okada, 2005). Therefore, the mainshock (\#1) and the largest aftershock (\#5) were probably caused by dislocations of parts 
of the Suwatoge Flexure and the Muikamachi Fault, respectively.

Hirata et al. (2005) determined hypocenters of $\sim 600$ aftershocks by using data from their rapidly deployed array of 14 stations. Kato et al. (2005) applied a double-difference tomography to a combined dataset of the same data as Hirata et al. (2005) used and data from 28 permanent stations, and obtained hypocenters of $\sim 700$ aftershocks and 3-D velocity models for the $P$ - and $S$-waves. They identified three major source faults. The source faults of the mainshock and the largest aftershock were parallel, steep west-dipping faults located $\sim 5 \mathrm{~km}$ apart. The source fault of the major aftershock on 27 October was perpendicular to the westdipping faults. These features are consistent with our results mentioned in Section 3.2.

A tectonic inversion from a tensional to a compressional stress field took place at 7 or 6 Ma (Takeuchi, 1977). Then the compressional stress became intense from $1 \mathrm{Ma}$ (Takano, 2002), which formed the Higashiyama and Uonuma Hill Zones by folding the relatively soft marine sediments. It also formed complicated reverse faults in this region, some of which were activated and caused the sequence of the 2004 Mid Niigata Prefecture Earthquake as shown in Fig. 5. In addition, the source area is located in the Niigata-Kobe Tectonic Zone with large contraction rates and had accumulated enough strain energy. These features are probably a main cause that many large aftershocks occurred in the sequence.

\section{Conclusions}

In order to obtain the detailed aftershock distribution of the 2004 Mid Niigata Prefecture Earthquake, we relocated the hypocenters with the JHD technique using the $P$ - and $S$-arrival times from the three temporary online stations and the 57 permanent stations in and around the source area.

We found the large differences in the travel time residuals between the Niigata Basin (positive) and the Echigo Mountains (negative), which caused biases $(\sim 3 \mathrm{~km}$ in the east-southeast and $\sim 3 \mathrm{~km}$ downwards) in the original JMA hypocenters. Our relocated hypocenters were considered to be improved in absolute accuracy.

The obtained aftershock distribution showed that at least the mainshock, the largest aftershock and the aftershock on 27 October were generated by the different fault planes which were nearly parallel or perpendicular to each other. This must be one of the causes that the aftershock activity contained many larger events.

Acknowledgments. We are very grateful to people in Tochio City, Ojiya City, Yamakoshi Village and Niigata Prefecture who kindly helped us in the aftershock observation. We thank Yuta Asaka, Ling Bai, Mio Hori, Takeshi Katagi, Shigemitsu Matsuo, Koichi Miura, Masahiro Morita, Sun Cheon Park and Atsushi
Watanabe for their help in the observation, and Aiko Nakao for her help in picking up the arrival times. We benefited from the thoughtful reviews of Haruhisa Nakamichi and an anonymous reviewer. We utilized waveform data from permanent stations operated by NIED, JMA and University of Tokyo and $P$ - and $S$-arrival times from the JMA preliminary catalog. The Generic Mapping Tools (Wessel and Smith, 1991) was used for drawing figures. This work was partially supported by Special Coordination Funds for Promoting Science and Technology, from Ministry of Education, Sport, Culture, Science and Technology.

\section{References}

Geographical Survey Institute, The Mid Niigata prefecture Earthquakes in 2004, http://cais.gsi.go.jp/Research/topics/topic041023/topic_041023. html, 2004.

Hirata, N., H. Sato, S. Sakai, A. Kato, and E. Kurashimo, Fault system of the 2004 Mid Niigata prefecture earthquake and its aftershocks, Landslides, 2(2), doi:10.1007/s10346-005-0050-8, 2005.

Japan Meteorological Agency, http://www.seisvol.kishou.go.jp/eq/ kyoshin/jishin/041023_niigata/1756/nigata_main.htm, 2004.

Kato, A., E. Kurashimo, N. Hirata, S. Sakai, T. Iwasaki, and T. Kanazawa, Imaging the source region of the 2004 mid-Niigata prefecture earthquake and the evolution of a seismogenic thrust-related fold, Geophys. Res. Lett., 32, L07307, doi:10.1029/2005GL022366, 2005.

Kim, H. Y., Relationship between the upheaval process of the Uonuma Hills and the cumulative nature of the Muikamachi fault, central Japan, Active Fault Res., 24, 63-75, 2004.

Kim, H. Y. and A. Okada, Surface deformations associated with the October 2004 Mid-Niigata earthquakes: Description and Discussion, Earth Planets Space, 2005 (submitted).

Kissling, E., W. L. Ellsworth, D. Eberhart-Phillips, and U. Kradolfer, Initial reference models in local earthquake tomography, J. Geophys. Res., 99, 19635-19646, 1994.

National Research Institute for Earth Science and Disaster Prevention (NIED), Earthquake mechanism information, http://www.fnet. bosai.go.jp/freesia/event/hypo/200410.html and 200411.html, 2004.

Ozawa, T., S. Nishimura, Y. Wada, and H. Ohkura, Coseismic deformation of the Mid Niigata prefecture Earthquake in 2004 detected by RADARSAT/InSAR, Earth Planets Space, 57, 423-428, 2005.

Sagiya, T., S. Miyazaki, and T. Tada, Continuous GPS array and presentday crustal deformation of Japan, Pure Appl. Geophys., 157, 23032322, 2000.

Takano, O., Changes in depositional systems and sequences in response to basin evolution in a rift and inverted basin: an example from the Neogene Niigata-Shin'etsu basin, North Fossa Magna, central Japan, Sedimentary Geology, 152, 79-97, 2002.

Takeuchi, A., Stress field and tectonic process during the Neogene and later period in the northern part of Nagano Prefecture, central Japan, $J$. Geol. Soc. Jpn., 83, 679-691, 1977 (in Japanese with English abstract).

Ueno, H., S. Hatakeyama, T. Aketagawa, J. Funasaki, and N. Hamada, Improvement of hypocenter determination procedures in the Japan Meteorological Agency, Quater. J. Seismol., 65, 123-134, 2002 (in Japanese with English abstract).

Urabe, T., N. Hirata, and K. Takano, A nation-wide seismic telemetry network in Japan using satellite communication, EOS, 79(45), F569, 1998.

Wessel, P. and W. H. F. Smith, Free software helps map and display data, EOS, Trans., Am. Geophys. Union, 72, 441, 1991.

T. Shibutani (e-mail: shibutan@rcep.dpri.kyoto-u.ac.jp), Y. Iio, S. Matsumoto, H. Katao, T. Matsushima, S. Ohmi, F. Takeuchi, K. Uehira, K. Nishigami, B. Enescu, I. Hirose, Y. Kano, Y. Kohno, M. Korenaga, Y. Mamada, M. Miyazawa, K. Tatsumi, T. Ueno, H. Wada, and Y. Yukutake 